\title{
Determinants of Intermittent Preventive Treatment with Sulfadoxine-Pyrimethamine in Pregnant Women (IPTp-SP) in Mali, a household survey.
}

\section{Oumar Sangho ( $\sim$ osangh2005@gmail.com )}

Université des Sciences, des Techniques et des Technologies de Bamako https://orcid.org/0000-00032856-0395

\section{Moctar Tounkara}

Universite des Sciences des Techniques et des Technologies de Bamako Faculte de Medecine et d'Odontostomatologie

\section{Lillian Joyce Whiting-Collins}

Johns Hopkins University Bloomberg School of Public Health

Madeleine Beebe

Johns Hopkins University Bloomberg School of Public Health

\section{Peter J. Winch}

Johns Hopkins University Bloomberg School of Public Health

\section{Seydou Doumbia}

Universite des Sciences des Techniques et des Technologies de Bamako Faculte de Medecine et d'Odontostomatologie

\section{Research}

Keywords: Access to care, geographic access, Intermittent Preventive Treatment, Malaria in pregnancy, antenatal care

Posted Date: July 14th, 2020

DOl: https://doi.org/10.21203/rs.3.rs-41058/v1

License: (c) (i) This work is licensed under a Creative Commons Attribution 4.0 International License. Read Full License 


\section{Abstract}

Background: In malaria endemic regions, Intermittent Preventive Treatment with SulfadoxinePyrimethamine (IPTp-SP) is recommended for all pregnant women during prenatal consultation from the fourth to the ninth month of pregnancy, up to the time of delivery. The Government of Mali is aiming for universal coverage of IPTp-SP. However, coverage is still low, estimated to be $18 \%$ for completion of three doses (IPTp-SP3). The objective of this study was to identify the factors that influence IPTp-SP in the Health District of Sélingué, Mali.

Methods: We performed a cross-sectional survey with 30 clusters, proportional to village size with two stages of sampling. We collected data electronically with Magpi software during face-to-face interviews/surveys. The data were analyzed with SPSS version 20 . We performed a descriptive analysis, and bivariate and multivariate logistic regression. An equity analysis examined the effect of distance from health care facility on completion of three or more antenatal visits (ANC3+) and three or more doses of Intermittent Preventive Treatment (IPTp-SP3+).

Results: Of the 1,021 women surveyed, $87.8 \%(n=896)$ attended at least one ANC visit. Of these, $86.3 \%(n$ $=773$ ) received at least 1 dose of IPTp-SP. The frequency of three or more ANC visits was $90.8 \%$. Compliance with three or more malaria treatments was $63.7 \%$. The determinants statistically related to ANC3+ were the early initiation of ANC $(\mathrm{OR}=3.22[1.22,10.78])$, the number of payments made for the malaria treatment $(\mathrm{OR}=21.5[2.64 ; 09], \mathrm{OR}=11.24[2.5,50.46])$ and the presence of a Community Health Center $(\mathrm{CHC})$ in the village $(\mathrm{OR}=9.69[1.09,86.21])$. The ability to read $(\mathrm{OR}=1.60[1.01,2.55])$, the early initiation of ANC (OR = $1.46[1.06,2.00]$, knowledge of the utility of the drug $(\mathrm{OR}=2.38[1.24,4.57])$, and knowledge of the recommended dose of the drug $(\mathrm{OR}=6.11[3.98,9.39])$ were related to completion of three or more treatments (IPTp-SP3+).

Conclusion: The early initiation of ANC was a good determinant of the completeness of ANC3+ and IPTp$\mathrm{SP} 3+$. Coverage was fair, but still far from universal. Alternative strategies are needed to further increase coverage.

\section{Background}

Malaria is a major public health problem. At the global level, there are approximately 3.3 billion people susceptible to malaria infection (1). In 2015, the number of malaria cases was estimated at 212 million (2). Of these cases $90 \%$ were recorded by the World Health Organization (WHO) Africa region, followed by the South-East Asia region (7\%) and Eastern Mediterranean region (2\%) (2). Of the 429,000 malaria deaths worldwide, $92 \%$ were recorded in Africa (1). Malaria is especially detrimental to the health and well-being of women and children (3). It can lead to maternal anemia, which increases the risk of hemorrhage during childbirth (3). In some endemic areas, malaria can directly contribute up to $25 \%$ of all maternal death (3). Malaria during pregnancy also increases the risk of miscarriage and affects fetal development, as well as preterm birth and low birth weight (4). Every year, 27.6 million pregnancies lead 
to live births in malaria-endemic areas in Africa (5). It is estimated that, in the absence of prevention, 12.4 million of those would be exposed to malaria infection (5).

As part of antenatal care (ANC) services, every effort should be made to improve access to SulfadoxinePyrimethamine Intermittent Preventive Treatment (IPTp-SP) everywhere in Africa where malaria endemicity level ranges from moderate to strong (6-8). The WHO recommends at least four ANC visits during pregnancy $(6,8)$. Starting as early as possible in the second trimester, IPTp-SP is recommended for all pregnant women at each ANC visit until delivery, and doses should be administered at least one month apart (8). Sulfadoxine-Pyrimethamine (SP) should not be administered during the first trimester of pregnancy (8). The last dose of IPTp-SP can be administered up to the time of delivery without any safety concern $(6,8)$. IPTp-SP should preferably be administered in the form of three SP tablets, under direct observation, which is the total required dosage of $1500 \mathrm{mg} / 75 \mathrm{mg}$ (8). SP can be administered with or without food (8). SP should not be given to women receiving prophylactic treatment with Cotrimoxazole because of a higher risk of adverse events (8). Globally, the percentage of women receiving IPTp-SP during pregnancy has increased over the years, although it remains below targets (1). IPTp-SP has been adopted by 37 countries (1). In these countries, $57 \%$ of pregnant women received at least one dose of IPTp-SP in 2013 , but only $17 \%$ received three doses or more (1). In 20 countries with sufficient data, $31 \%$ of eligible pregnant women received at least 3 doses of IPTp-SP in 2015, compared to $6 \%$ in 2010 (2). A meta-analysis of 27 countries in 2011 estimated IPTp-SP compliance to be $21.5 \%$ (95\% Cl 19.3-23.7) across sub-Saharan Africa (9).

In Mali, the objective of the National Policy for Malaria Control, led by the National Malaria Control Program (PNLP), is to achieve universal coverage of SP through free distribution to pregnant women countrywide (10). The main goal of the 2013-2017 Strategic Plan of the PNLP (7) is to ensure universal access to prevention measures for $100 \%$ of the population at risk of malaria, including the use of IPT by pregnant women (7). Hurley's secondary analysis of the 2012-2013 Demographic and Health Survey (DHSM-V) data (11) shows that $56.2 \%$ and $29.9 \%$ of recently pregnant women benefited from IPTp-SP1 and TPlg-SP2+, respectively, in Mali (12). The Malaria Indicators Survey conducted in Mali in 2015 (EIPM) shows adherence of $66.4 \%$ for IPTp-SP1, $44.4 \%$ for IPTp-SP2 and $21 \%$ for IPTp-SP3+ (13). In the Sikasso Region, the adherence of IPTp-SP1 was $68.42 \%$ and that of IPTp-SP2 and IPTp-SP3 $+50.8 \%$ and $26.8 \%$, respectively (14). In 2015 the EIPM showed an adherence of $68.7 \%, 44.4 \%$ and $22.2 \%$ respectively for IPTp-SP1, IPTp-SP2 and IPTp-SP3+ (13). In Sélingué, in 2016, 72\% of pregnant women had received IPTp-SP1 compared to $43 \%$ for IPTp-SP2 and only $19 \%$ for IPTp-SP3 (15). Based on these data, the goals of the national malaria control program (PNLP) have not been achieved. In the Malian healthcare system, ANC provides women with the opportunity to get IPTp-SP. The frequencies were $74 \%$ for ANC1 and $41 \%$ for ANC4 and above (ANC4+) at national level. In the Sikasso region they were $79 \%$ for ANC1 (11). In Sélingué, in 2017, the frequencies of ANC1, ANC3 and ANC4 were $89 \%, 26 \%$ and $28 \%$ respectively (15).

Several studies have explored the determinants of the use and completeness of IPTP-SP $(9,12,16-31)$. Nonattendance and/or completeness of ANC is considered a key determinant of IPTp-SP coverage (15, 16, 21, 24). A qualitative study conducted in Mali in 2013 identified the following factors influencing the 
completeness of the 2 doses of IPTp-SP: late use or non-use of ANC services, perception of malaria during pregnancy, poor acceptability of SP, stock-outs of SP, and insufficient information on the policy of providing SP free of cost to pregnant women (16). In spite of this free IPTp national distribution policy, the authors reported variations in IPTp costs at various health facilities, and during prenatal visits (16). Lack of education and economic wellbeing have also been identified as factors influencing the use of IPTp-SP, with high level of education, level of economic well-being, and living in an urban area strongly associated with women taking IPTp-SP (9). In 2013, a meta-analysis was done which included 98 articles and 20 intervention studies from 1990 to 2013 (24). The results suggested that barriers to the use of IPTp-SP included lack of clarification of guidelines and policy, poor organization of services, stock-outs, costs of health services, lack of competent health workers, and the underuse of ANC by women (24). Key determinants of IPTp-SP were level of education, knowledge of malaria and IPTp-SP, socio-economic status, parity, and number of and early initiation of ANC visits (24). Despite knowledge of the factors affecting completeness of IPTP-SP, frequencies remain low. It is necessary to find an alternative strategy to improve IPTp-SP coverage. We conducted this study to identify the factors that specifically influence IPTp-SP in the Sélingué Health District in an effort to inform local efforts to improve IPTp-SP.

\section{Methods}

\section{Site}

The study was conducted in the health district of Sélingué, located $120 \mathrm{~km}$ southwest of Bamako. The health district of Sélingué was composed of seven subdistricts: Kangaré, Binko, Siékorolé, Tanga, Carrière, Diarani and Faraba during our study period. Currently there are nine subdistricts. The population was 91,425 in 2012, across 60 villages (32). The dam on the Sankarani River, a branch of the Niger River, has created an artificial lake of $409 \mathrm{~km}^{2}$ in Sélingué, making rice cultivation, gardening, and fishing the main activities in the area (33). There were 18 community health workers (CHW) in the district; each working with several community relays (CR) and traditional birth attendants in each village (34). CHW were involved in minor medical care for children under 5 years of age and in the education and referral of pregnant women to ANC services.

\section{Design}

We conducted a cross-sectional survey with cluster sampling proportional to village population size at two levels. Thus, the number of clusters per village depended on the population size in each village. A total of thirty clusters were needed to have a representative sample. Overall, 960 households were selected for the 30 clusters (each cluster consisted of 32 households with at least one eligible woman). The minimum sample size was 981 households. To be eligible, the woman must have had a pregnancy in the two years prior to the survey, regardless of pregnancy outcome, according to the same selection process used in the EIPM and the sixth Demographic and Health Surveys (DHS-VI) $(13,14)$. Participants were interviewed face-to-face by interviewers and were shown the 3 SP tablets to see if they recognized them. 


\section{Data quality management and control}

All data were collected on tablets by six data collectors and two supervisors (enumerators), during one month, using Magpi remote data collection software (35). Data collectors were trained by the supervisors. The tools have been pre-tested in Diago village near Bamako. Data were checked by the enumerator, uploaded to a secure cloud-based server, and later exported to an Excel spreadsheet by data manager. Data were then analyzed in SPSS software version 20 (36).

\section{Data analysis}

Our analysis focused on the following two outcomes:

1. Completion of 3 or more antenatal consultations (ANC3+): Women who completed at least three ANC visits were coded 1 , and those who did not were coded 0 . These women should have received IPTpSP1+ (Fig. 1). We considered only women who achieved ANC3+, because with the current national policy, a woman may have obtained all three doses of IPTp-SP without completing the ANC4 +.

1. IPTp-SP3 + intake: Women who received at least 3 doses of IPTP-SP were coded 1, and 0 if they did not receive the 3 doses. These women were those who have completed their ANC3+ (Fig. 1).

We conducted bivariate analyses according to the flow presented in Fig. 1. Bivariate analysis for the outcome of IPTp-SP3 + intake included women who completed ANC1, IPTp-SP1 and ANC3+; and was performed using Chi square tests and simple logistic regression. We estimated odds ratios (OR) with 95\% confidence intervals $(95 \% \mathrm{Cl})$ and verified the association between dependent and independent variables (age, level of education, parity, Distance from the village to $\mathrm{CHC}$, possibility to read (literacy), Age of pregnancy at the first ANC, Knowledge of the usefulness of SP, Knowledge of the recommended SP dose, Knowledge of the period of starting taking SP, SP payment number, Given Insecticide Treated Nets (ITN) in ANC, Presence of $\mathrm{CHC}$ in the village, Rurality of the village of residence, Poverty quintile) using the Kendall tau B correlation (37). Variables that had a significant association during the bivariate analysis were selected for the multivariate (global) model. We performed multiple logistic regression and presented adjusted odds ratios (ORa) with a p value of 0.05 . We assessed correlation between the independent variables with Kendall's tau $B$ and eliminated variables that demonstrated strong correlations. For ANC3+, we added the variable "ability to read" due to its importance for understanding of medical information.

To measure equity in terms of geographic accessibility to facilities providing ANC, we used the Gini index and the concentration curve (CC). These data analysis tools are recognized as standard measures employed by health economists to estimate wealth inequity on various health indicators (38-45). We adapted these tools in our study to estimate inequities in health services utilization according to geographic accessibility. Geographic accessibility was measured using the distance index between a woman's village of residence and the $\mathrm{CHC}$. This index places women's villages of residence individually on a continuous scale of relative distance. Villages have been grouped into five distance quintiles. 
Distance quintiles were used to compare the influence of distance on ANC3 + and IPTp-SP3+. Principal component and factor analysis were used to determine quintiles of poverty. The original line (oblique or diagonal) shows perfect equity. The more the second line curves away from the perfect equity line, the higher the degree of inequity is. A curve below the equity line indicates a disproportionate use of services for households from villages close to health facilities. Although the concentration curve is a useful tool for the graphical representation of inequity, it does not quantify the magnitude of inequity. Hence the use of The Gini Index, which is a quantitative measure of inequity in the use of health care. It was used by Wagstaff A \& van Doorslaer $E$ in 2004 to measure the degree of inequity associated with household wealth (45). The value of the index varies between -1 and +1 . A value of 0 indicates that the use of health services is equitably distributed among socio-economic groups (46). In this case the confidence interval around the index value includes zero. If zero is not within the confidence interval, there is a statistically significant inequity in the use of health services (46). A negative value of the concentration index implies greater use among the more remote health facilities while a positive value indicates that women in villages around health facilities have greater coverage than women far from health facilities.

\section{Results}

The analysis included 1,021 women. Table 1 shows the socio-demographic characteristics of the study sample. More than a quarter of women surveyed (26.2\%) were between 20-24 years old. Many women $(68.7 \%)$ had no level of education. Multiparas were the most frequent with $61.1 \%$. Most of the women surveyed (73.4\%) lived within $5 \mathrm{~km}$ of a CHC. Figure 1 shows the flow chart of the completeness of ANC3 + and IPTp-SP3+. 
Table 1

Sociodemographic characteristics of women surveyed in 2016 Sélingué District, Mali $(N=1021)$

\begin{tabular}{|ccc|}
\hline Sociodemographic Variables & $\mathbf{n}$ & $\%$ \\
\hline Age groups & & \\
\hline $15-19$ & 247 & 24,2 \\
\hline $20-24$ & 268 & 26,2 \\
\hline $25-29$ & 212 & 20,8 \\
\hline $30-34$ & 154 & 15,1 \\
\hline $35-39$ & 103 & 10,1 \\
\hline $40-49$ & 37 & 3,6 \\
\hline Level of education & & \\
\hline No level of education & 701 & 68,7 \\
\hline Primary 1 & 213 & 20,9 \\
\hline Primary 2 & 88 & 8,6 \\
\hline At least secondary level & 19 & 1,9 \\
\hline Parity & & \\
\hline Primipara & 199 & 19,5 \\
\hline Secondi parous & 197 & 19,3 \\
\hline Multiparous & 625 & 61,2 \\
\hline Geographic accessibility & & \\
\hline Distance from the village to CHC & & \\
\hline 0 to 5 km & 749 & 73,4 \\
\hline 6 to 15 km & 169 & 16,6 \\
\hline$>15$ km & 10,1 \\
\hline
\end{tabular}

\section{Bivariate and multivariate analysis}

Tables 2 and 3 present results from the bivariate and multivariate analyses for ANC3 + and IPTp-SP3+. Kendall tau $\mathrm{B}$ analysis revealed a negative correlation $(-0.048)$ between the presence of $\mathrm{CHC}$ in the woman's village of residence and the rurality of the village of residence. There was a positive correlation (0.131) between knowledge of the recommended SP dose and knowledge of when to start taking SP, $\mathrm{p}<$ 0.0001 . There was a positive correlation (0.432) between knowledge of the recommended SP dose and 
the number of payments for $\mathrm{SP}, \mathrm{p}<0.0001$. The knowledge of the recommended dose was correlated to two variables. We have therefore decided to remove it from the multivariate analysis presented in Table 2. We conducted a similar analysis for IPTp-SP3+. There was a positive correlation (0.121) between knowledge of the benefit of taking SP and the knowledge of the recommended dose, $p=0.001$. There was a positive correlation ( 0.441 ) between knowledge of the recommended doses of SP and the number of payments, $p<0.0001$. We therefore decided to remove the knowledge of the recommended dose from the multivariate analysis for IPTp-SP3 + from Table 3. 
Table 2

Bivariate and multivariate analysis: Predictive variables of ANC3 + among women surveyed in 2016, Sélingué, Mali

\begin{tabular}{|c|c|c|c|c|}
\hline Characteristics & $\mathrm{n}$ & $\begin{array}{l}\text { ANC3 + } \\
\mathrm{n}(\%)\end{array}$ & OR [Cl 95\%] & ORa [Cl 95\%] \\
\hline Can read & 773 & & & \\
\hline No & 661 & $599(90,6)$ & - & 1 \\
\hline Yes & 112 & $103(92,0)$ & - & $1,04[0,2 ; 5,56]$ \\
\hline Age of pregnancy at the first ANC & 757 & & & \\
\hline 4 months or more & 444 & $385(86,7)$ & 1 & 1 \\
\hline 3 months or less & 313 & $306(97,8)$ & $\begin{array}{l}6,7 * \star \star \\
14,88]\end{array}$ & $\begin{array}{l}3,62 *[1,22 \\
10,78]\end{array}$ \\
\hline $\begin{array}{l}\text { Knowledge of the recommended SP } \\
\text { dose }\end{array}$ & 773 & & & \\
\hline Incorrect answer & 538 & $476(88,5)$ & 1 & - \\
\hline Know the recommended dose & 235 & $226(96,2)$ & $3,27 * \star \star[1,6 ; 6,7]$ & - \\
\hline $\begin{array}{l}\text { Knowledge of the period of starting } \\
\text { taking SP }\end{array}$ & 773 & & & \\
\hline Incorrect answer & 665 & $597(89,8)$ & 1 & 1 \\
\hline 4 months or less & 108 & $105(97,2)$ & $\begin{array}{l}3,99 *[1,23 \\
12,91]\end{array}$ & $\begin{array}{l}5,41[0,67 \\
43,93]\end{array}$ \\
\hline SP payment number & 280 & & & \\
\hline 1 time & 112 & $84(75,0)$ & 1 & 1 \\
\hline 2 times & 71 & $70(98,6)$ & $\begin{array}{l}23,33^{\star *}[3,1 \\
175,84]\end{array}$ & $\left.\begin{array}{l}21,5 * \star \\
175,09\end{array}\right] 2,64 ;$ \\
\hline 3 times or more & 97 & $95(97,9)$ & $\begin{array}{l}15,83^{* \star \star}[3,66 \\
68,47]\end{array}$ & $\begin{array}{l}11,24 * \star \\
50,46]\end{array}$ \\
\hline Given ITN in ANC & 772 & & & \\
\hline No & 210 & $183(87,1)$ & 1 & 1 \\
\hline Yes & 562 & $519(92,3)$ & $1,78 *[1,07 ; 2,97]$ & $1,51[0,62 ; 3,7]$ \\
\hline Presence of $\mathrm{CHC}$ in the village & 773 & & & \\
\hline CHC planned but not operational & 22 & $17(77,3)$ & 1 & 1 \\
\hline \multicolumn{5}{|l|}{$\star=p<0,05 ; * \star=p<0,01 ; * \star \star=p \leq 0,001$} \\
\hline $\mathrm{OR}=$ Odds Ratio. $\mathrm{ORa}=$ Adjusted $\mathrm{Od}$ & o. & & & \\
\hline
\end{tabular}




\begin{tabular}{|c|c|c|c|c|}
\hline Characteristics & $\mathbf{n}$ & $\begin{array}{l}\text { ANC3 + } \\
\text { n(\%) }\end{array}$ & OR [Cl 95\%] & ORa [Cl 95\%] \\
\hline Village with $\mathrm{CHC}$ & 282 & $257(91,1)$ & $3,02 *[1,03 ; 8,89]$ & $\begin{array}{l}9,69 *[1,09 ; \\
86,21]\end{array}$ \\
\hline No planned or operational $\mathrm{CHC}$ & 469 & $428(91,3)$ & $3,07 *[1,08 ; 8,75]$ & $7,8[0,98 ; 62,4]$ \\
\hline Rurality of the village of residence & 773 & & & \\
\hline Rural & 448 & $420(93,8)$ & 1 & 1 \\
\hline Less rural & 325 & $282(86,8)$ & $0,44 * *[0,27 ; 0,72]$ & $0,69[0,27 ; 1,77]$ \\
\hline \multicolumn{5}{|l|}{$*=p<0,05 ; * *=p<0,01 ; * \star *=p \leq 0,001}$. \\
\hline \multicolumn{5}{|c|}{ OR = Odds Ratio. $\mathrm{ORa}=$ Adjusted Odds Ratio. } \\
\hline
\end{tabular}


Table 3

Bivariate and multivariate analysis: Predictive variables of IPTp-SP3 + among women surveyed in 2016, Sélingué, Mali

\begin{tabular}{|c|c|c|c|c|}
\hline Characteristics & $\mathbf{n}$ & $\begin{array}{l}\text { IPTp-SP3 + } \\
\text { n(\%) }\end{array}$ & OR [Cl 95\%] & ORa [Cl 95\%] \\
\hline Poverty quintile & 697 & & & \\
\hline Q1 (poorest) & 128 & $85(66,4)$ & 1 & 1 \\
\hline Q2 (poorer) & 140 & $92(65,7)$ & $0,97[0,58 ; 1,61]$ & $1,5[0,24 ; 9,25]$ \\
\hline Q3 (mean) & 142 & $100(70,4)$ & $1,20[0,72 ; 2,01]$ & $1,23[0,24 ; 6,15]$ \\
\hline Q4 (wealthier) & 146 & $79(54,1)$ & $0,60 *[0,37 ; 0,97]$ & $0,17 *[0,03 ; 0,92]$ \\
\hline Q5 (most wealthy) & 141 & $87(61,7)$ & $0,82[0,49 ; 1,34]$ & $0,48[0,09 ; 2,54]$ \\
\hline Can read & 701 & & & \\
\hline No & 599 & $373(62,3)$ & 1 & 1 \\
\hline Yes & 102 & $74(72,5)$ & $1,60 *[1,01 ; 2,55]$ & $\begin{array}{l}10,27 *[1,52 \\
69,28]\end{array}$ \\
\hline $\begin{array}{l}{ }^{1} \text { Age of pregnancy at the first } \\
\text { ANC }\end{array}$ & 690 & & & \\
\hline 4 months or more & 384 & $229(59,6)$ & 1 & 1 \\
\hline 3 months or less & 306 & $209(68,3)$ & $1,46 *[1,06 ; 2,00]$ & $1,58[0,53 ; 4,72]$ \\
\hline $\begin{array}{l}\text { Knowledge of the usefulness of } \\
\text { SP }\end{array}$ & 700 & & & \\
\hline Incorrect answer & 641 & $399(62,2)$ & 1 & 1 \\
\hline Prevention of malaria & 59 & $47(79,7)$ & $2,38 * \star[1,24 ; 4,57]$ & $1,32[0,2 ; 8,76]$ \\
\hline $\begin{array}{l}{ }^{1} \text { Knowledge of the recommended } \\
\text { SP dose }\end{array}$ & 701 & & & \\
\hline Incorrect answer & 475 & $250(52,6)$ & 1 & - \\
\hline $\begin{array}{l}\text { Know the recommended } \\
\text { dose }\end{array}$ & 226 & $197(87,2)$ & $6,11 * \star \star[3,98 ; 9,39]$ & - \\
\hline${ }^{1} \mathrm{SP}$ payment number & 249 & & & \\
\hline 1 time & 84 & $16(19,0)$ & 1 & 1 \\
\hline
\end{tabular}

$*=p<0,05 ; * *=p<0,01 ; * * *=p \leq 0,001$.

$\mathrm{OR}=$ Odds Ratio. $\mathrm{ORa}=$ Adjusted Odds Ratio. 


\begin{tabular}{|c|c|c|c|c|}
\hline Characteristics & $\mathbf{n}$ & $\begin{array}{l}\text { IPTp-SP3 + } \\
\text { n(\%) }\end{array}$ & OR [Cl 95\%] & ORa [Cl 95\%] \\
\hline 2 times & 70 & $66(94,3)$ & $\begin{array}{l}70,13^{* * *}[22,28 ; \\
220,76]\end{array}$ & $\begin{array}{l}139,18 * \star * \\
588,06]\end{array}$ \\
\hline 3 times or more & 95 & $92(96,8)$ & $\begin{array}{l}130,33^{* * \star}[36,52 ; \\
465,18]\end{array}$ & $\begin{array}{l}244,73^{* \star \star}[54,28 ; \\
1103,5]\end{array}$ \\
\hline $\begin{array}{l}{ }^{1} \text { Rurality of the village of } \\
\text { residence }\end{array}$ & 701 & & & \\
\hline Rural & 419 & $287(68,5)$ & 1 & 1 \\
\hline Less rural & 282 & $160(56,7)$ & $0,60 * *[0,44 ; 0,82]$ & $0,17 * \star[0,05 ; 0,57]$ \\
\hline \multicolumn{5}{|c|}{$*=p<0,05 ; * *=p<0,01 ; * \star *=p \leq 0,001}$. \\
\hline $\mathrm{OR}=$ Odds Ratio. $\mathrm{ORa}=\mathrm{A}$ & s Rá & & & \\
\hline
\end{tabular}

\section{Equity and distance to $\mathrm{CHC}$}

Figures 2 and 3 present the results of the equity analysis for completeness adherence to ANC + and IPTp-SP3 + under the influence of distance from women's home villages to $\mathrm{CHC}$. Women close to $\mathrm{CHC}$ were more likely to complete ANC3 + and IPTp-SP3 + than those far from the $\mathrm{CHC}$, although this inequity was not statistically significant (Table 4).

Table 4

Concentration index of the realization of ANC3 + and IPTp-SP3 + in the women surveyed in 2016, Sélingué, Mali.

\begin{tabular}{|lllll|}
\hline $\begin{array}{l}\text { Concentration index } \\
\text { (CIndex) }\end{array}$ & $\begin{array}{l}\text { Variance of } \\
\text { Clndex }\end{array}$ & $\begin{array}{l}\text { Standard } \\
\text { Error }\end{array}$ & $\begin{array}{l}\mathbf{t} \\
\text { Statistic }\end{array}$ & $\begin{array}{l}95 \% \text { Confidence Interval } \\
\text { (Cl) }\end{array}$ \\
\hline ANC3+ & & & & \\
\hline 0,1641 & 0,0072 & 0,0850 & 1,9306 & {$[-0,0025 ; 0,3307]$} \\
\hline IPTp-SP3+ & & & & \\
\hline 0,1584 & 0,0096 & 0,0980 & 1,6168 & {$[-0,0336 ; 0,3504]$} \\
\hline
\end{tabular}

\section{Discussion}

We used the same selection process of women as in the MICS and the DHS-V $(11,13)$. We chose ANC3 + as a dependent variable because from three ANC visits it is possible to have an adherence of IPTp-SP3+ (6-8). This choice allowed women who had missed opportunities to benefit from IPTp-SP to be excluded from the determinants analysis, as Hurley reported (12).

\section{Frequency of ANC3 + and IPTp-SP3+}


ANC is the entry point for the women included in this study to benefit from the WHO recommended intervention package $(6,8,38)$ for their protection and that of their fetus as mentioned in the conclusion of Hill's 2013 study and others $(12,17,47)$. Our study's frequencies of ANC1+ $(87.8 \%)$ and ANC3+ $(68.8 \%)$ were fairly good compared to those found in the fifth DHS of Mali in the Sikasso region (14), and those of ANC1 (78.3\%) found in van Eijk's meta-analysis of 26 sub-Saharan African countries (9). Our findings are also higher than Hill's estimates of $81 \%$ of ANC1 among recently pregnant women and $63 \%$ of ANC1 among pregnant women in Segou (17). However, ANC1 frequency in our study was similar to that of the Sélingué data from the 2016 statistical yearbook (15).

We found an IPTp-SP3 + frequency of $63.7 \%$ among women who completed ANC3+, which is similar to the one that Muhumuza E. obtained in Uganda (29). This frequency was greater than $38.5 \%$ of Odjidja(48), but less than 71\% of Ibrahim and al. (49) both in Ghana in 2017.

Furthermore, we found a high frequency of IPTp-SP3 + contrary to our expectation at the beginning of the study and high compared to the frequencies of the 2015 MICS of $19 \%$ in Sikasso (13), the statistical yearbook 2016 of $19.1 \%$ in Sélingué (15) and data in most other studies $(9,12,17,25,26,29,46,50,51)$. For instance, Hill found $28.6 \%$ for IPTp-SP2 + and $47.8 \%$ for IPTp-SP1 in Segou (17).

The high frequency of IPTp-SP is related to several factors. Sélingué District is an area that has benefited from the presence of a research unit of the National Institute of Research in Public Health and the intervention of Non-Governmental Organizations (NGOs) including Borne Fonden. We can also mention the implementation of the project "Integrated control of malaria based on an environmental and community base in agro-ecosystems of West Africa" in 2012 and 2013 as an influencing factor (52). During this project, an awareness raising campaign on ANC was conducted through local radio stations (52). Additionally, the Village Malaria Committees and Farmers Field school served as a means for information, education, and action (52). Also, the presence of Community Health Workers (CHW) and Village Health Volunteers (VHV) has helped to raise awareness. Notably, in 2014, the CHW conducted 1,660 home visits involving 5,464 people (69.6\% of whom were women), 1,369 discussion and sharing sessions, and 544 counseling sessions for 16,486 people ( $82 \%$ of whom were women) (53).

Since the implementation of the policy of 3 or more doses of SP started in Sélingué in 2014, before our survey, it is possible that the women surveyed obtained the number of doses they mentioned. Many women surveyed recognized the 3 SP tablets that the investigators were showing them. Some of them said its local name (sumaya fura kisè saaba). But this recognition was not always followed by the awareness of its usefulness. The investigators did not say the name in advance, to make sure the woman recognized them. We considered women's assertions based on the Kappa concordance test obtained by Hill J. et al. in Segou in 2014 (17). Another fact is that, after our study, the WHO guidance changes from "at least four ANC visit" to "eighth visits". This change could influence future study on the number of IPTp-SP.

Our study may have also benefited from the policy shift in IPTp-SP with the possibility of taking up to the time of delivery starting at 4 months. This could be an explanation of the observed frequency. Moreover, 
our investigation, to our knowledge, is the first that covered the whole district of Sélingué, and the first to cover an entire district in Mali.

\section{Determinants of ANC3+}

The participants who reported knowledge of the usefulness of taking SP and had started taking SP earlier in their pregnancies were more likely to benefit from ANC3 + compared to those who did not know of SP's usefulness or who did not take it early in pregnancy. This theory is reinforced by the education and literacy level; women's level of education as a predictor of ANC compliance is supported by the literature $(18,22)$.

Distance to facility was a barrier to the completeness of ANC3+, as found in the literature $(12,54,55)$. This is why women in villages with $\mathrm{CHC}$ were significantly more likely to achieve their ANC3 + compared to those in villages without CHC. An analysis of data from 10 West African countries in 2016 found that distance, in addition to poverty, level of education, and rurality of the village of residence, were barriers to ANC utilization as well as effectiveness (56).

Additionally, the 2016 Statistical Yearbook identified the following factors to explain low rates of ANC: the late initiation of reproductive health services, inadequate completion of monitoring forms, insufficient qualified staff in peripheral reproductive health services, insufficient active research, inadequate reception, and poor communication (15).

Surprisingly, buying SP was found to be a positive determinant of the completeness of ANC3 + in our study. However, in other studies $(12,16,50,54)$, buying SP and other charges have been identified as barriers to ANC.

\section{Determinants of the observance of IPTp-SP3+}

ANC is the entry point for a woman to benefit from IPTp-SP. In our study, the $12.2 \%$ of women who did not have any antenatal visit were less likely to receive IPTp-SP. Among those who had received ANC, 13.5\% had not received SP. ANC appears as a fundamental barrier to both the use and the completeness of IPTpSP3+. Those two factors (any ANC and any IPTp-SP during ANC) were also identified as a barrier in a study conducted by Hurley in 2016 (12). Similarly, a study by Sangaré in 2010 found that $68.7 \%$ of women eligible for IPTp-SP2 did not take any or simply had a single dose of IPTp-SP (20).

Our study found that relatively wealthy women were significantly (40\%) less likely to complete IPTp-SP3 + compared to poor women as opposed to what is generally observed in the literature (27) where adherence is proportional to wealth level. Women who were educated, who knew the usefulness of SP and the correct dose of SP were significantly more likely to complete IPTp-SP3+. Similar findings were reported by Hill in Mali, Ameh and Onyeneho in Nigeria, and Kibusi in Tanzania $(17,25,27,57)$. The compliance with IPTp-SP3 + therefore appears proportional to the level of education. Hill in his systematic review and meta-analysis found that having the correct information on IPTP-SP increased the likelihood of taking the SP (24). Pell, in the same way, found that lack of knowledge was a barrier to IPTp-SP (58). 
We found that starting ANC early was a good indicator of IPTp-SP3 + compliance, which reinforces findings from other studies $(17,24,27)$. However, with the current recommendations (8), a woman can have 3 doses (IPTp-SP3+) even if she started her ANC at 6-7 months, taking SP every month, provided there is regular attendance at ANC visits after this late start. In this case, this indicator could, in the future, no longer serve as an adequate good indicator of compliance.

The Direct Observed Therapy (DOT) of SP, as recommended (6-8), was not widely practiced in Sélingué compared to findings of other studies $(26,59)$. Half of the participants in our study had practiced the DOT of SP. The other half took their SP home for self-administration, in absence of observer, contrary to the recommendations (6-8). The absence of observed treatment represents a barrier to good IPTp-SP3 + compliance as confirmed by the literature $(17,18,24-26)$. Few women were aware that SP can be taken on an empty stomach. Unavailability of drinking fountain or cups by the fountain as well as asking women if they had eaten prior to coming to the health center influenced the nonobservance of DOT of IPTp-SP. That suggests the lack of competence of health workers on the guidelines for the administration of SP as identified by van Eijk (9). Similarly, Mubyazi (60) found that the lack of clean water and cups were barriers to the DOT of SP. In another study, some pregnant women brought their own water bottle to the health center to take SP, which enabled a barrier to DOT of SP (26). Other authors found the influence of availability of drinking water on the DOT of SP $(18,28)$, hence we reiterate recommendations for the availability of clean water and cups to improve the DOT (50). Additionally, as noncompliance with DOT of IPTp-SP guidelines has been identified in several studies $(12,16,17,20,24)$, a need for competence building is largely suggested $(19,24,27,61)$.

Distance was also identified as a barrier to IPTp-SP3 + in our study, and was confirmed by our equity analysis. Women in $\mathrm{CHC}$ village sites were more likely to complete IPTp-SP3 + compared to women in villages far from the $\mathrm{CHC}$. These findings are supported by those in the study by Hurley (12). However, our findings conflict with Hill's study that women in villages close to $\mathrm{CHC}$ were less likely to complete IPTp-SP (17).

We found that purchasing SP was a facilitator of IPTp-SP3 + completeness. This trend was confirmed by the number of payments mentioned by the participants in our study. The higher the number of payments for SP, the more likely the woman complete IPTp-SP3+, which appeared paradoxical in our context. The national guidelines suggest that SP must be delivered to pregnant women free of charge $(6,8,62)$. However, paying for SP did not appear as a barrier in our study. Payment of SP was reported by women in the study carried out by Klein (16) in Koulikoro and Sikasso, Mali, which support the comments made by the participants in our study. Klein found that payment was one barrier for the IPTp-SP2 + and that even staff were confused about IPTp-SP being free of charge (16). In addition to the fact that the payment is probable, other possible explanations concerning this affirmation of payment of the SP would be: 1) the husbands or attendants were in charge of the payment of the prescription given to the women; 2 ) difficulties to differentiate between paid and free drugs; 3 ) the husbands or attendants didn't share with women the information on the policy of offering SP free of cost; 4) lack of clear explanations of free medicines by staff, or 5) free drugs are not available from the ANC agent but rather from the pharmacy. 
Some of these explanations are corroborated by the studies of Hurley and Hill $(12,24)$. It should be noted that the guidelines recommend both predisposing the free SP in the ANC units instead of the pharmacy and, on the other hand, making the separate SP prescription (62). This is not always done in CHC. We noted a very wide confidence of SP payment number (Table 3 ). Future research could explore this relationship more.

\section{Equity Analysis}

Our findings suggested that distance impacts the completeness of ANC3 + and IPTp-SP3+. The appearance of our curves (Figs. 2 and 3 ) indicated inequities in favor of women in the villages closest to the $\mathrm{CHCs}$, especially after the first quintile of distance. Women nearer were more likely to complete ANC3 + and IPTp-SP3 + than those who were distant.

\section{Study limitations}

The IPTp-SP questions did not specify exactly which dose was targeted because it was not standardized on a specific dose such as the first dose taken, or the last dose taken. The woman could answer on any dose. The IPTp-SP questions were asked only to women who said they had received ANC. Those who did not attend ANC could have interesting information, especially multiparas, hence a potential source of selection bias. The cross sectional nature of the study and the subjective responses of the women surveyed could introduce information biases not only by the women themselves but also by the interviewers because of the length of the questionnaire, the time for the interview, and some skips or connection problems in the Magpi software used for electronic data collection. Lastly, we did not evaluate the availability of SP stock in the health centers. However, few women mentioned SP stock shortage at the $\mathrm{CHC}$ as the reason for not getting and taking SP.

\section{Conclusion}

Despite the high frequency of IPTp-SP3 + in our study, Mali is still far from the goal of universal coverage of pregnant women. We were able to identify several critical factors in achieving this goal. The positive factors include the level of education, the early start of ANC, the level of knowledge of IPTp-SP, and the observance of DOT at the CHC. Some of the barriers include the distance to the health facility, the lack of implementation of ANC, the unavailability of water for DOT, the lack of knowledge of the national policy guidelines and, the lack of good communication between health workers and pregnant women. To overcome these barriers, we recommend the following:

- Set up a community-based distribution system to improve geographic access to treatment;

- Train health workers on the simplified technical guidelines for offering Sulfadoxine-Pyrimethamine Presumptive Intermittent Therapy;

- Reinforce the direct observed treatment of Intermittent Presumptive Sulfadoxine-Pyrimethamine.

\section{List Of Abbreviations}




\begin{tabular}{|ll|}
\hline ANC & Antenatal care or antenatal visits \\
\hline CHC & Community Health Center \\
\hline CHW & community health workers \\
\hline CHW & Community Health Workers \\
\hline Cl & Confident Interval \\
\hline CIndex & Concentration index \\
\hline CR & community relays \\
\hline DHS & Demographic and Health Surveys (DHS \\
\hline DOT & Direct Observed Therapy \\
\hline EIPM (MICS) & Malaria Multiple Indicators Cluster Survey \\
\hline IPTp-SP & Intermittent Preventive Treatment with Sulfadoxine-Pyrimethamine \\
\hline ITN & Insecticide Treated Nets \\
\hline NGOs & Non-Governmental Organizations \\
\hline OR & Odds Ratio \\
\hline ORa & Adjusted Odds Ratio \\
\hline PNLP & National Malaria Control Program \\
\hline SPSS & Statistical Package for the Social Sciences \\
\hline VHV & Village Health Volunteers \\
\hline WHO & World Health Organization \\
\hline
\end{tabular}

\section{Declarations}

\section{Ethics approval and consent to participate}

The study protocol was approved by both ethics committees of the Faculty of Medicine, Dentistry and Pharmacy of Mali ( $\left.N^{\circ} 2015 / 112 / C E / F M P O S\right)$ and John Hopkins University of Baltimore in the United States (FWA00000287). The research team members were trained in data collection techniques and questionnaires were pre-tested in a village out of the intervention area. Investigators did not collect participants' names or other personal identifiers. Informed consent was read in the local language and approval was obtained with a signature of participants. Married women aged 15 and over were considered adults with the legal power to give informed consent, as stated in Malian law. 


\section{Consent for publication}

Not applicable

\section{Availability of data and materials}

The datasets used and/or analysed during the current study are available from the corresponding author on reasonable request.

\section{Competing interests}

The authors declare that they have no competing interests.

\section{Funding}

This study was funded through a NIH R21 Grant from the Fogarty International Center (Grant Number 1R21TW009885-01).

The funder had no role in the design of the study and collection, analysis, interpretation of data, or in writing the manuscript.

\section{Authors' contributions}

OS analysed and interpreted data and write the manuscript. MT, LWC and MB and PJW analysed and interpreted data and reviewed the manuscript. SD review the manuscript. All authors read and approved the final manuscript.

\section{Acknowledgements}

The study authors gratefully acknowledge Dr Dadé Haidara, Chief of Sélingué Referral Health District during the survey and all the health care providers in the Community Health Centers, and the Community Health Workers and surveyors; Dr Craig Tower, Ms Wendy Yang, Ms Rachel Turkel, Dr Emily Hurley, Dr Ousmane Ly, Professor Hamadoun Sangho, Professor Akory Ag Iknane, Professor Cheick Oumar Bagayoko for their contribution to the review of the dissertation; Dr Lancina Doumbia and Ms Hannah Marker for the translation. We would also like to thank the Fogarty International Center for supporting Oumar Sangho Moctar Tounkara under Grant D43TW008652.

\section{References}


1. WHO. World Malaria Report 2014 [Internet]. WHO Geneva; 2014 [cité 23 déc 2017]. Disponible sur: https://www.who.int/malaria/publications/world_malaria_report_2014/report/en/.

2. WHO. World Malaria Report 2016 [Internet]. WHO Geneva; 2017 [cité 26 déc 2017]. Disponible sur: https://www.who.int/malaria/publications/world-malaria-report-2016/report/en/.

3. Schantz-Dunn J, Nour NM. Malaria and pregnancy: a global health perspective. Rev Obstet Gynecol. 2009;2(3):186.

4. Desai M, ter Kuile FO, Nosten F, McGready R, Asamoa K, Brabin B, et al. Epidemiology and burden of malaria in pregnancy. Lancet Infect Dis. 2007;7(2):93-104.

5. Walker PG, ter Kuile FO, Garske T, Menendez C, Ghani AC. Estimated risk of placental infection and low birthweight attributable to Plasmodium falciparum malaria in Africa in 2010: a modelling study. Lancet Glob Health. 2014;2(8):e460-7.

6. WHO. Intermittent preventive treatment in pregnancy (IPTp) [Internet]. WHO, Geneva; 2018 [cité 15 févr 2018]. Disponible sur: http://www.who.int/malaria/areas/preventive_therapies/pregnancy/en/.

7. Mali malaria PStrag

-17PNLP_0.pdf [Internet]. [cité 24 déc 2017]. Disponible sur

Mali malaria PStrag. 2013-17PNLP_0.pdf [Internet]. [cité 24 déc 2017]. Disponible sur: https://www.severemalaria.org/sites/www.severemalaria.org/files/content/attachments/2017-0725/Mali\%20malaria\%20PStrag\%202013-17PNLP_0.pdf.

8. WHO. Updated WHO policy recommendation: intermittent preventive treatment of malaria in pregnancy using sulfadoxine-pyrimethamine (IPTp-SP) [Internet]. WHO Geneva; 2014 [cité 3 avr 2016]. Disponible sur: http://www.who.int/malaria/publications/atoz/iptp-sp-updated-policy-brief24jan2014-an.pdf.

9. van Eijk AM, Hill J, Larsen DA, Webster J, Steketee RW, Eisele TP, et al. Coverage of intermittent preventive treatment and insecticide-treated nets for the control of malaria during pregnancy in subSaharan Africa: a synthesis and meta-analysis of national survey data, 2009-11. Lancet Infect Dis. 2013;13(12):1029-42.

10. Programme Nationale de Lutte contre le Paludisme. Politique Nationale de lutte contre le paludisme 2011-2015. Ministère de la Santé; 2011.

11. Enquête Démographique et de Santé au Mali 2012-2013 [Internet]. ICF International, Rockville, Maryland

[cité 24 déc 2017]. Disponible sur:

CPS/SSDSPF INSTAT. INFO-STAT. Enquête Démographique et de Santé au Mali 2012-2013 [Internet]. ICF International, Rockville, Maryland, USA; 2014 [cité 24 déc 2017]. Disponible sur: http://www.sante.gov.ml/index.php/annuaires/send/8-enquetes-demographiques-de-sante/4-eds-v2013.

12. Hurley EA, Harvey SA, Rao N, Diarra NH, Klein MC, Diop SI, et al. Underreporting and missed opportunities for uptake of intermittent preventative treatment of malaria in pregnancy (IPTp) in Mali. PloS One. 2016;11(8):e0160008. 
13. Programme National de Lutte contre le Paludisme (PNLP). Institut National de la Statistique (INSTAT), INFO-STAT, Institut National de la Recherche en Santé Publique (INRSP), ICF International. Enquête sur les Indicateurs du Paludisme au Mali (EIPM) 2015 [Internet]. Rockville, Maryland, USA: INSTAT, INFO-STAT et ICF International; 2016 [cité 28 avr 2018] p. 180. Disponible sur: https://www.dhsprogram.com/pubs/pdf/MIS24/MIS24.pdf.

14. Institut National de la Statistique (INSTAT), Cellule de Planification et de Statistique Secteur SantéDéveloppement Social et Promotion de la Famille (CPS/SS-DS-PF), ICF. Enquête Démographique et de Santé au Mali 2018 [Internet] Institut National de la Statistique (INSTAT), Cellule de Planification et de Statistique Secteur SantéDéveloppement Social et Promotion de la Famille (CPS/SS-DS-PF), ICF. Enquête Démographique et de Santé au Mali 2018 [Internet]. Bamako, Mali et Rockville, Maryland, USA: INSTAT, CPS/SSDS-PF et ICF. 2019 [cité 18 oct 2019] p. 385. Disponible sur:

https://www.dhsprogram.com/pubs/pdf/FR358/FR358.pdf.

15. Direction Régionale

Direction Régionale. de la Santé SLIS. Annuaire statistique 2016 de la Région de Sikasso. Sikasso; 2017.

16. Klein MC, Harvey SA, Diarra H, Hurley EA, Rao N, Diop S, et al. "There is no free here, you have to pay": actual and perceived costs as barriers to intermittent preventive treatment of malaria in pregnancy in Mali. Malar J. 2016;15(1):158.

17. Hill J, Kayentao K, Toure M, Diarwara S, Bruce J, Smedley J, et al. Effectiveness of antenatal clinics to deliver intermittent preventive treatment and insecticide treated nets for the control of malaria in pregnancy in Mali: a household survey. PLoS One. 2014;9(3):e92102.

18. Webster J, Kayentao K, Bruce J, Diawara SI, Abathina A, Haiballa AA, et al. Prevention of malaria in pregnancy with intermittent preventive treatment and insecticide treated nets in Mali: a quantitative health systems effectiveness analysis. PloS One. 2013;8(6):e67520.

19. Webster J, Kayentao K, Diarra S, Diawara SI, Haiballa AA, Doumbo OK, et al. A qualitative health systems effectiveness analysis of the prevention of malaria in pregnancy with intermittent preventive treatment and insecticide treated nets in Mali. PloS One. 2013;8(7):e65437.

20. Sangaré LR, Stergachis A, Brentlinger PE, Richardson BA, Staedke SG, Kiwuwa MS, et al. Determinants of use of intermittent preventive treatment of malaria in pregnancy: Jinja, Uganda. PLoS One. 2010;5(11):e15066.

21. Hill J, Dellicour S, Bruce J, Ouma P, Smedley J, Otieno P, et al. Effectiveness of antenatal clinics to deliver intermittent preventive treatment and insecticide treated nets for the control of malaria in pregnancy in Kenya. PLoS One. 2013;8(6):e64913.

22. Faye A, Manga NM, Seck I, Niang K, Leye MM, Diagne-Camara M, et al. Access to intermittent preventive treatment (IPT) in a situation of abolition of user's fee: role of economic welfare. Bull Soc Pathol Exot 1990. 2012;105(3):215-9. 
23. Florey L. Preventing malaria during pregnancy in sub-Saharan Africa: Determinants of effective IPTp delivery. 2013.

24. Hill J, Hoyt J, van Eijk AM, D'Mello-Guyett L, ter Kuile FO, Steketee R, et al. Factors affecting the delivery, access, and use of interventions to prevent malaria in pregnancy in sub-Saharan Africa: a systematic review and meta-analysis. PLoS Med. 2013;10(7):e1001488.

25. Ameh S, Owoaje E, Oyo-Ita A, Kabiru CW, Akpet OE, Etokidem A, et al. Barriers to and determinants of the use of intermittent preventive treatment of malaria in pregnancy in Cross River State, Nigeria: a cross-sectional study. BMC Pregnancy Childbirth. 2016;16(1):99.

26. Doku DT, Zankawah MM, Adu-Gyamfi AB. Factors influencing dropout rate of intermittent preventive treatment of malaria during pregnancy. BMC Res Notes. 2016;9(1):460.

27. Kibusi SM, Kimunai E, Hines CS. Predictors for uptake of intermittent preventive treatment of malaria in pregnancy (IPTp) in Tanzania. BMC Public Health. 2015;15(1):540.

28. Leonard N, Eric FB, Judith A-KK, Samuel W. Factors associated to the use of insecticide treated nets and intermittent preventive treatment for malaria control during pregnancy in Cameroon. Arch Public Health. 2016;74(1):5.

29. Muhumuza E, Namuhani N, Balugaba BE, Namata J, Kiracho EE. Factors associated with use of malaria control interventions by pregnant women in Buwunga subcounty, Bugiri District. Malar J. 2016;15(1):342.

30. Rassi C, Graham K, King R, Ssekitooleko J, Mufubenga P, Gudoi SS. Assessing demand-side barriers to uptake of intermittent preventive treatment for malaria in pregnancy: a qualitative study in two regions of Uganda. Malar J. 2016;15(1):530.

31. Rassi C, Graham K, Mufubenga P, King R, Meier J, Gudoi SS. Assessing supply-side barriers to uptake of intermittent preventive treatment for malaria in pregnancy: a qualitative study and document and record review in two regions of Uganda. Malar J. 2016;15(1):341.

32. Centre de Santé de Référence. Carte Sanitaire 2012 du District Sanitaire de Sélingué. Système Local d'Information Sanitaire (SLIS); 2012.

33. the free encyclopedia Wikipedia. the free encyclopedia. Sankarani River [Internet]. Disponible sur: http://en.wikipedia.org/wiki/Sankarani_River.

34. Centre de Santé de Référence. Tableau de bord et PARAD 2014 de Sélingué. Système Local d'Information Sanitaire (SLIS); 2015.

35. Magpi | Advanced

Mobile Data Collection and Visualization [Internet]

[cité 8 nov 2019]. Disponible sur

Magpi | Advanced. Mobile Data Collection and Visualization [Internet]. [cité 8 nov 2019]. Disponible sur: https://home.magpi.com.

36. SPSS Statistics 20 Available for Download [Internet]. 2014 [cité 8 nov 2019]. Disponible sur: https://www.ibm.com/support/pages/spss-statistics-20-available-download. 
37. Laerd Statistics

Kendall's Tau-b using SPSS Statistics [Internet]

Laerd Statistics. Kendall's Tau-b using SPSS Statistics [Internet]. 2013 [cité 3 janv 2018]. Disponible sur: https://statistics.laerd.com/spss-tutorials/kendalls-tau-b-using-spss-statistics.php.

38. Shaw R, Ainsworth M. Financing health services through user fees and insurance, case studies from Sub-Saharan Africa. Washington: World Bank; 1995.

39. WHO. WHO | Equity [Internet]. WHO. 2014 [cité 2 janv 2018]. Disponible sur: http://www.who.int/healthsystems/topics/equity/en/.

40. Kunst AE, Houweling T. A global picture of poor-rich differences in the 10. Utilization of delivery care. Studies in Health Services Organization and Policy [Internet]. 2001. Disponible sur:

https://www.researchgate.net/publication/254733871_A_global_picture_of_poorrich_differences_in_the_utilisation_of_delivery_care.

41. Graham WJ, Fitzmaurice AE, Bell JS, Cairns JA. The familial technique for linking maternal death with poverty. The Lancet. 2004;363(9402):23-7.

42. Zere E, Tumusiime P, Walker O, Kirigia J, Mwikisa C, Mbeeli T. Inequities in utilization of maternal health interventions in Namibia: implications for progress towards MDG 5 targets. Int J Equity Health. 2010;9(1):16.

43. El-Khoury M, Hatt L, Gandaho T. User fee exemptions and equity in access to caesarean sections: an analysis of patient survey data in Mali. Int J Equity Health. 2012;11(1):49.

44. The DHS Wealth Index: DHS Comparative Reports [Internet] [cité 2 janv 2018]. Disponible sur Rutstein SO, Johnson K. The DHS Wealth Index: DHS Comparative Reports [Internet]. Calverton, Maryland USA. 2004 [cité 2 janv 2018]. Disponible sur: https://dhsprogram.com/pubs/pdf/cr6/cr6.pdf.

45. Hossain MI. Inequality in the utilization of maternal care and the impact of a macroeconomic policy: Evidence from Bangladesh. HEDG WorNing Pap. 2010;10(08).

46. Wagstaff A, Van Doorslaer E. Measuring and testing for inequity in the delivery of health care. J Hum Resour. 2000;716-733.

47. Ndyomugyenyi R, Katamanywa J. Intermittent preventive treatment of malaria in pregnancy (IPTp): do frequent antenatal care visits ensure access and compliance to IPTp in Ugandan rural communities? Trans R Soc Trop Med Hyg. 2010;104(8):536-40.

48. Odjidja E, Kwanin C, Saha. Low Uptake of Intermittent Preventive Treatment in Ghana; An Examination of Health System Bottlenecks. Health Syst Policy Res Vol. 2017;4:58.

49. Ibrahim H, Maya ET, Issah K, Apanga PA, Bachan EG, Noora CL. Factors influencing uptake of intermittent preventive treatment of malaria in pregnancy using sulphadoxine pyrimethamine in Sunyani Municipality, Ghana. Pan Afr Med J. 2017;28.

50. Chico RM, Dellicour S, Roman E, Mangiaterra V, Coleman J, Menendez C, et al. Global Call to Action: maximize the public health impact of intermittent preventive treatment of malaria in pregnancy in 
sub-Saharan Africa. Malar J. 2015;14(1):207.

51. Kiwuwa MS, Mufubenga P. Use of antenatal care, maternity services, intermittent presumptive treatment and insecticide treated bed nets by pregnant women in Luwero district, Uganda. Malar J. 2008;7(1):44.

52. Seydou Doumbia E, Fondjo M, Halidou S, Diop. Oumar Sangho. Rapport technique final Projet « Le contrôle intégré du paludisme basé sur une base environnementale et communautaire dans les agrosystèmes de l'Afrique de l'Ouest ». Bamako: USTTB; 2013. pp. déc.

53. Système Local d'Information Sanitaire (SLIS). Rapport Mensuel d'Activités (RMA) 2014 des sites ASC. Selingué: Centre de Santé de Référence de Sélingué; 2015.

54. Simkhada B, Teijlingen ER van, Porter M, Simkhada P. Factors affecting the utilization of antenatal care in developing countries: systematic review of the literature. J Adv Nurs. 2008;61(3):244-60.

55. Gabrysch S, Campbell OM. Still too far to walk: literature review of the determinants of delivery service use. BMC Pregnancy Childbirth. 2009;9(1):34.

56. Taylor YJ, Laditka SB, Laditka JN, Huber LRB, Racine EF. Associations of household wealth and individual literacy with prenatal care in ten West African countries. Matern Child Health $\mathrm{J}$. 2016;20(11):2402-10.

57. Onyeneho NG, Orji BC, Okeibunor JC, Brieger W. Characteistics of Nigerian women taking sulfadoxine/pyrimethamine twice during pregnancy for the prevention of malaria. International Journal of Gynecology and Obstetrics. 2013;101-4.

58. Pell C, Straus L, Andrew EV, Meñaca A, Pool R. Social and cultural factors affecting uptake of interventions for malaria in pregnancy in Africa: a systematic review of the qualitative research. PloS One. 2011;6(7):e22452.

59. Mubyazi G, Bloch P, Kamugisha M, Kitua A, ljumba J. Intermittent preventive treatment of malaria during pregnancy: a qualitative study of knowledge, attitudes and practices of district health managers, antenatal care staff and pregnant women in Korogwe District, North-Eastern Tanzania. Malar J. 2005;4(1):31.

60. Mubyazi GM, Magnussen P, Goodman C, Bygbjerg IC, Kitua AY, Olsen ØE, et al. Implementing intermittent preventive treatment for malaria in pregnancy: review of prospects, achievements, challenges and agenda for research. Open Trop Med J. 2008;1:92.

61. Mbonye AK, Yanow S, Birungi J, Magnussen P. A new strategy and its effect on adherence to intermittent preventive treatment of malaria in pregnancy in Uganda. BMC Pregnancy Childbirth. 2013;13(1):178.

62. PNLP MSHP/Mali. Directives Nationales sur la gestion et la distribution gratuite des Moustiqueaires Imprées d'insectivie de Longue Durée; de la Sulfadoxine Pyriméthamine et la Chimioprévention du Paludisme Saisonnier. PNLP; 2016.

\section{Figures}




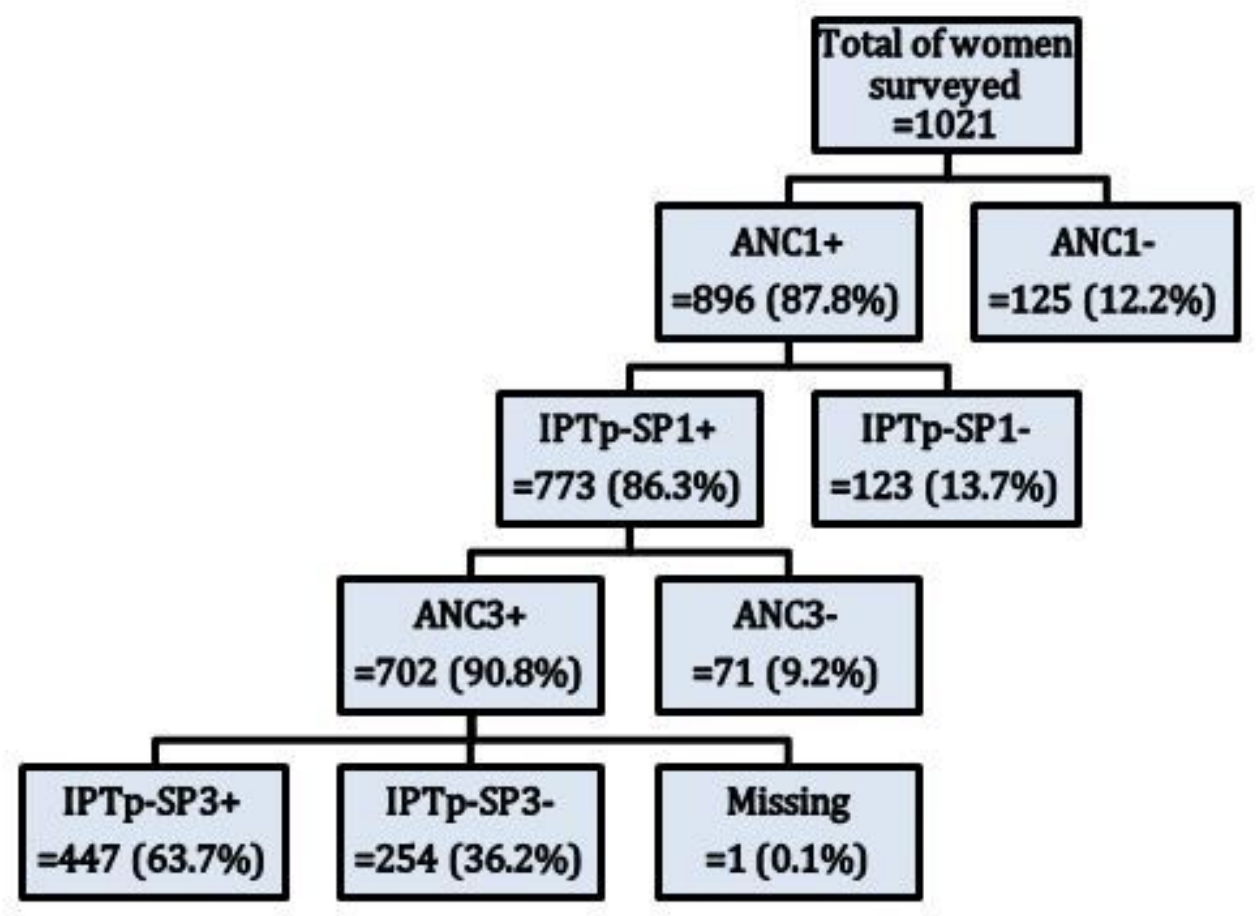

Figure 1

Flow diagram of IPTp-SP intake among women surveyed in 2016, Sélingué, Mali

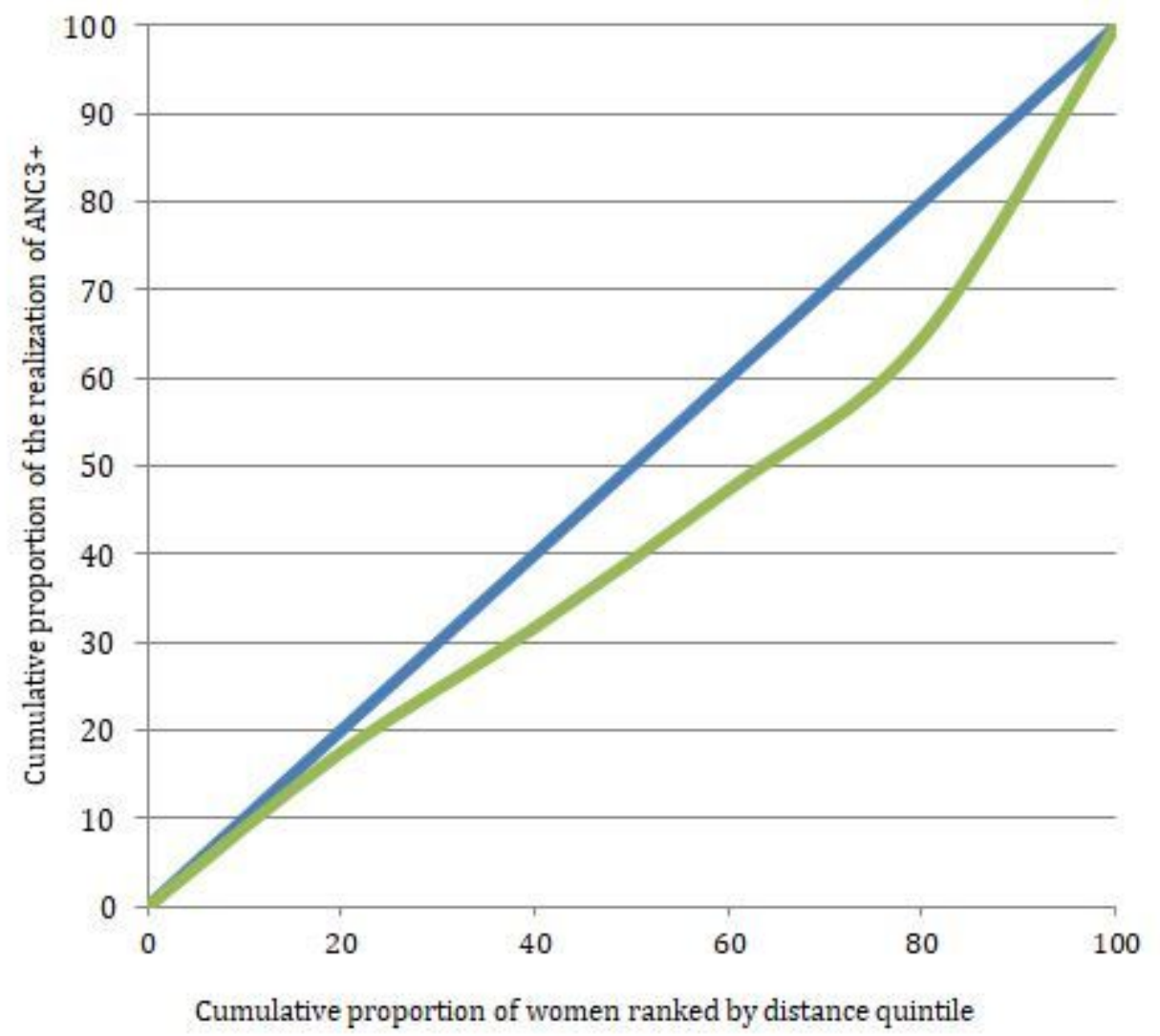

Figure 2 
Curve of concentration of the realization of ANC3+ in the women surveyed in 2016, Sélingué, Mali.

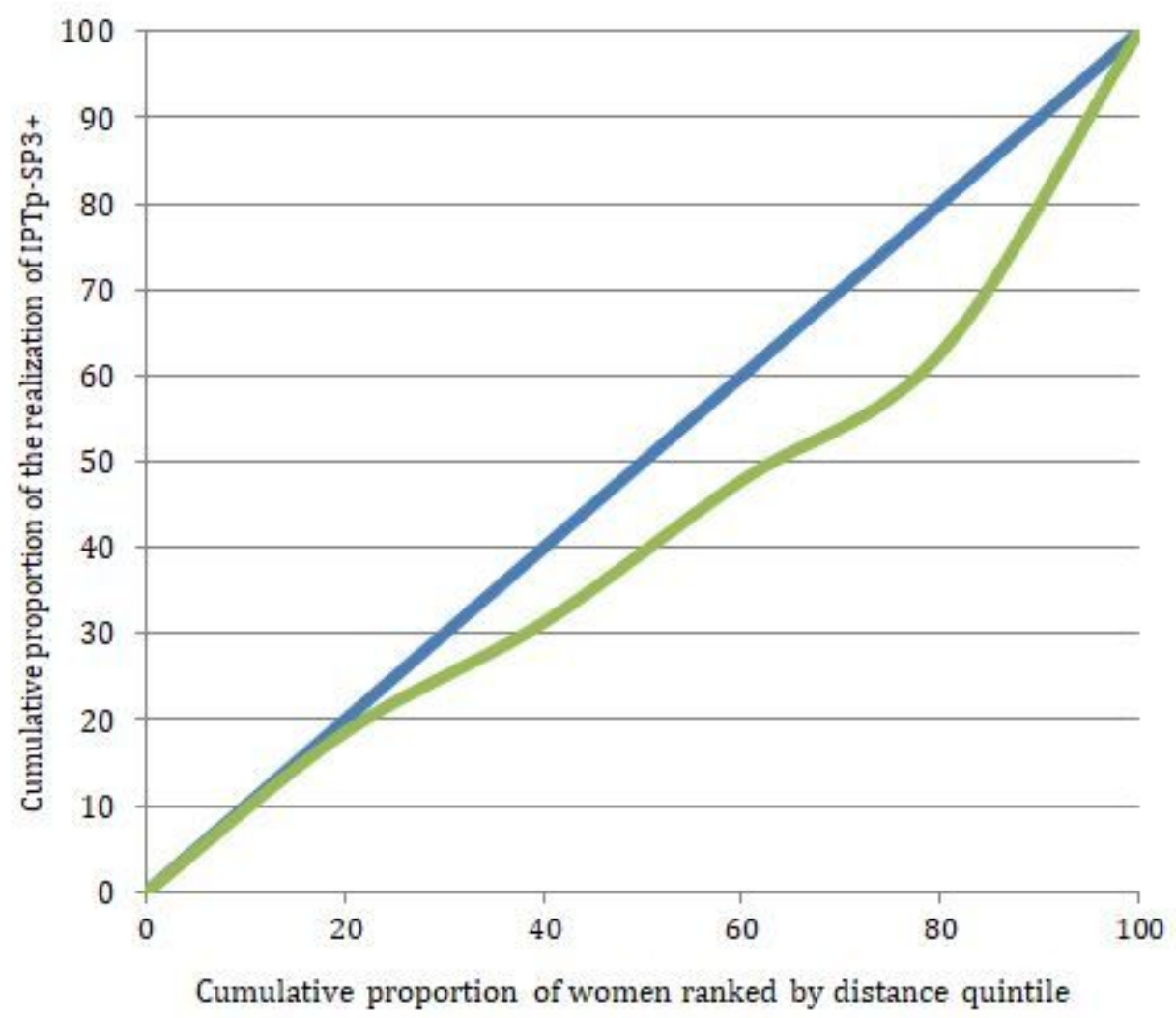

Figure 3

Curve of concentration of the realization of IPTp-SP3+ in the women surveyed in 2016, Sélingué, Mali. 